\title{
How to Interpret a Functional or Motility Test - Sphincter of Oddi Manometry
}

\author{
Young Koog Cheon \\ Digestive Disease Center, Department of Internal Medicine, Konkuk University School of Medicine, Seoul, Korea
}

To date, endoscopic manometry is the best method for evaluating the function of the sphincter. Sphincter of Oddi manometry (SOM) remains the gold standard to correctly diagnose the sphincter of Oddi dysfunction (SOD) and stratify therapy. Several dynamic abnormalities relating to the intensity, frequency, and propagation of sphincter contractions have been described. However, their clinical use generally has been abandoned in favor of basal sphincter pressure alone, because this measurement is stable over time, and has stronger interobserver reliablility, reproducibility on repeating testing, and is associated with the responsiveness to therapy. A significant elevated risk of pancreatitis was attributed to the technique. The risk of pancreatitits associated with manometric evaluation of the pancreatic sphincter is markedly reduced when manometry is performed with continous aspiration from the pancreatic duct via one of the 3 catheter lumens. This section reviews indications, conscious sedative drugs, techniques, and the appropriate interpretations of SOM.

(J Neurogastroenterol Motil 2012;18:211-217)

\section{Key Words}

Manometry; Pancreatitis; Sphincter of Oddi; Sphincter of Oddi dysfunction

\section{Introduction}

Sphincter of Oddi dysfunction (SOD) refers to an abnormality of sphincter of Oddi (SO) contractility. It is a benign, noncalculous obstruction to flow of bile or pancreatic juice through the pancreatobiliary junction, ie, the $\mathrm{SO}$ that causes pain and may or may not be associated with pancreatitis, abnormal liver tests, and dilated ducts. ${ }^{1,2}$ Two types of SOD have been proposed on the basis of pathogenic mechanisms: stenosis and dyskinesia. ${ }^{3,4}$ $\mathrm{SO}$ stenosis is a structural abnormality in which there is narrowing in part or all of the sphincter because of chronic inflammation and fibrosis. It is associated with pancreatitis or injury from gallstone migration through the papilla, trauma from intraoperative manipulation of the common bile duct, or nonspecific inflammatory conditions. SO dyskinesia refers to a primary motor abnormality of the $\mathrm{SO}$ which may result in a hypertonic sphincter. Because it is often impossible to distinguish patients with SO dyskinesia from those with $\mathrm{SO}$ stenosis, the term SOD has been used to incorporate both groups of patients. In an attempt to deal with this overlap in etiology, and also to determine the appropriate utilization of $\mathrm{SO}$ manometry (SOM), a clinical classification system has been developed for patients with suspected SOD (Table 1). ${ }^{5}$

Received: January 28, 2012 Revised: February 24, 2012 Accepted: March 4, 2012

(c) This is an Open Access article distributed under the terms of the Creative Commons Attribution Non-Commercial License (http://creativecommons. org/licenses/by-nc/3.0) which permits unrestricted non-commercial use, distribution, and reproduction in any medium, provided the original work is properly cited.

*Correspondence: Young Koog Cheon, MD, PhD Digestive Disease Center, Department of Internal Medicine, Konkuk University School of Medicine, 120-1 Neungdong-ro, Gwangjin-gu, Seoul 143-729, Korea

Tel: +82-2-2030-8195, Fax: +82-2-2030-5029, E-mail: yksky001@hanmail.net

Financial support: None.

Conflicts of interest: None. 
Table 1. Hogan-Geenen Sphincter of Oddi Classification System Related to the Frequency of Abnormal Sphincter of Oddi Manometry and Pain Relief by Biliary Sphincterotomy

\begin{tabular}{|c|c|c|c|c|}
\hline \multirow[t]{2}{*}{ Patient group classification } & \multirow{2}{*}{$\begin{array}{l}\text { Frequency of } \\
\text { abnormal sphincter } \\
\text { manometry }\end{array}$} & \multicolumn{2}{|c|}{$\begin{array}{l}\text { Probability of pain relief by } \\
\text { sphincterotomy if manometry }\end{array}$} & \multirow{2}{*}{$\begin{array}{l}\text { Manometry before } \\
\text { sphincter ablation }\end{array}$} \\
\hline & & Abnormal & Normal & \\
\hline $\begin{array}{l}\text { Biliary I }(\%) \\
\text { Biliary-type pain } \\
\text { Abnormal AST or ALP }>\times 2 \text { normal } \\
\text { Delayed drainage of ERCP contrast from the biliary tree }>45 \text { min } \\
\text { Dilated CBD }>12 \mathrm{~mm} \text { diamter }\end{array}$ & $75-95$ & $90-95$ & $90-95$ & Unnecessary \\
\hline $\begin{array}{l}\text { Biliary II }(\%) \\
\text { Biliary-type pain } \\
\text { Only } 1 \text { or } 2 \text { of the above criteria }\end{array}$ & $55-65$ & 85 & 35 & $\begin{array}{l}\text { Highly } \\
\text { recommended }\end{array}$ \\
\hline $\begin{array}{l}\text { Biliary III (\%) } \\
\text { Only biliary-type pain }\end{array}$ & $25-60$ & $55-65$ & $<10$ & Mandatory \\
\hline
\end{tabular}

AST, aspartate aminotransferase; ALP, alkaline phosphatase; ERCP, endoscopic retrograde cholangiopancreatography; CBD, common bile duct.

\section{Sphincter of Oddi Manometry}

$\mathrm{SOM}$ is the only available method to measure $\mathrm{SO}$ motor activity directly. Additionally, it is the only modality for diagnosis of suspected SOD which has been demonstrated to be reproducible and predictive of positive therapeutic outcome results. SOM is usually performed at the time of endoscopic retrograde cholangiopancreatography (ERCP).

\section{Indications}

SOM is recommended in patients with idiopathic pancreatitis or unexplained disabling pancreaticobiliary pain with or without hepatic enzyme abnormalities. The Rome III committee ${ }^{6}$ concluded that biliary (and pancreatic) pain classically occurs in recurrent episodes of steady, severe, pain located in the epigastrium and/or the right upper abdominal quadrant lasting $\geq 30$ minutes, and not relieved by bowel movements, postural changes, or antacids. In the abscence structural diseases (eg, gallstones, pancreatitis or malignancy), such pains may be the clinical presentation which have originated from gallbladder or SOD.

Indications for the use of SOM have also been developed according to the Hogan-Geenen SOD classification system (Table 1). In Type I patients, there is a general consensus that a structural disorder of the sphincter (ie, sphincter stenosis) exists. Although SOM may be useful in documenting SOD, it is not an essential diagnostic study prior to endoscopic or surgical sphincter ablation. Such patients uniformly benefit from sphincterotomy regardless of the SOM results. Type II patients demonstrate $\mathrm{SO}$ motor dysfunction in $50 \%$ to $65 \%$ of cases. In this group of patients, SOM is highly recommended as the results of the study predict outcome from sphincterotomy. Type III patients have pancreaticobiliary pain without other objective evidence of sphincter outflow obstruction. SOM is mandatory to confirm the presence of SOD. Although not well studied, it appears that the results of SOM may predict outcome from sphincter ablation in these patients.

Many endoscopists assumed that post-ERCP pancreatitis after SOM was related to pancreatic duct manipulation. They therefore first obtained selective cannulation of the biliary tree and then performed SOM, assuring avoidance of pancreatic duct manometry. However, there is no evidence suggesting that this approach reduces the risk of pancreatitis, but a reasonable amount of data now suggests that some patients have isolated sphincter abnormalities, and mandates both ducts to be studied for complete evaluation of the SO. ${ }^{7,8}$ In a series of 360 patients with pancreatobiliary pain, $19 \%$ had abnormal pancreatic sphincter pressure alone, $11 \%$ had abnormal biliary basal sphincter pressure alone and in $31 \%$ both the biliary and pancreatic pressures were elevated. ${ }^{8}$ Hence, both the bile duct and pancreatic duct must be evaluated to obtain complete assessment of the SO.

\section{Methods}

\section{Premedications and Sedations}

Performance of SOM requires significant experience on 
both ERCP and manometric testing. All drugs which relax (anticholinergics, nitrates, calcium channel blockers and glucagon) or stimulate (narcotics or cholinergic agents) the sphincter should be avoided for at least 8-12 hours prior to manometry and during the manometric session. ${ }^{1}$ Recently, I found that phosphodiesterase type 5 inhibitors (eg, sildenafil, vardenafil and tadalafil), which have been used to treat erectile dysfunction, inhibits SO motility in patients with suspected SOD. ${ }^{9}$ Diazepam (benzodiazepines), long the sole standard agent used for performance of SOM, has no significant effect on normal SO motility, ${ }^{10,11}$ but its effect on hypertensive sphincters is unknown. Previously published controlled trials of midazolam compared with saline solution injection during sedation with diazepam demonstrate significant reductions in both normal and elevated basal pressures and in peak phasic pressures but not in phasic wave amplitude, frequency or propagation. ${ }^{12}$ Based on these results, investigators have advised that midazolam should not be used for sedation during SOM. Only limited studies are reported on the effect of propofol on sphincter pressures. A study that used a canine model demonstrated no significant effect when small bolus doses $(<5 \mathrm{mg} / \mathrm{kg}$ ) were administered, but elevations in both duodenal activity and SO basal and phasic pressures and contraction frequencies were observed with higher doses. ${ }^{13}$ Meperidine, at a dose of $\leq 1 \mathrm{mg} / \mathrm{kg}$, does not affect the basal sphincter pressure. ${ }^{14}$ It was suggested that meperidine could be used to facilitate conscious sedation for manometry.

\section{Sphincter of Manometry Technique}

\section{Manometry catheters and manometor}

There are currently 3 types of manometric pressure record-

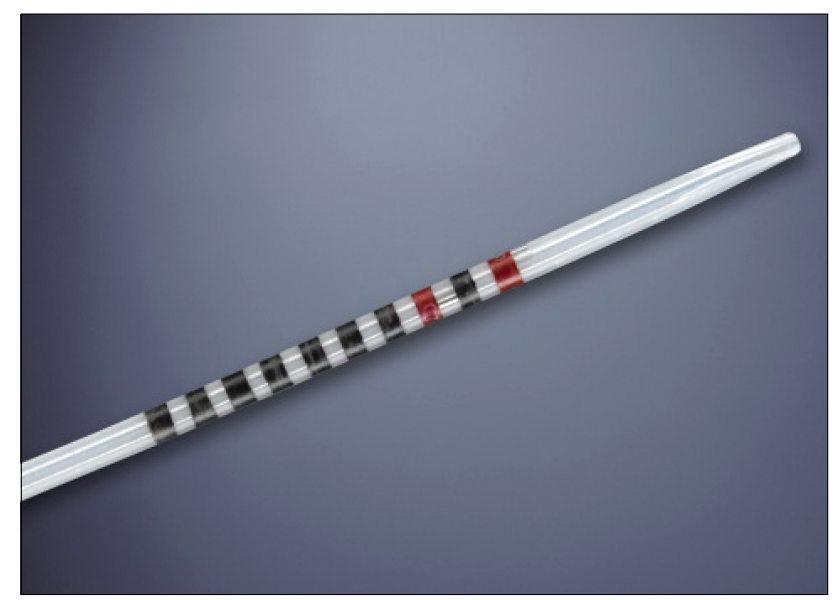

Figure 1. Sphincter of Oddi catheter. Triple-lumen catheter with a long intraductal tip helps secure the catheter within the bile duct. ing catheters used in SOM studies. Five-French catheters should be used, since virtually all standards have been established with these catheters. Triple-lumen $(1.7 \mathrm{~mm})$ catheters are state of the art and are available from several manufacturers. Catheters with a long intraductal tip may help secure the catheter within the bile duct, but such a long nose is commonly a hindrance if pancreatic manometry is desired. Some triple-lumen catheters will accomodate a 0.018 inch diameter guidewire through the entire length of the catheter and can be used to facilitate cannulation or maintain position in the duct (Lehman sphincter manometry catheter; Cook Endoscopy, Winston-Salem, NC, USA) (Fig. 1). Pancreatitis, a potentially serious consequence of this procedure, has been reported. A modified triple lumen $5 \mathrm{Fr}$ SOM catheter (aspiration catheter) has been developed in an attempt to reduce the risk of pancreatitis. ${ }^{15} \mathrm{~A}$ modified catheter allowed continuous decompression by gentle syringe aspiration (using a 3 or $5 \mathrm{~mL}$ syringe) through an end hole and side hole, while recording pressures from the 2 other ports (Fig. 2).

The perfused systems utilize the Arndorfer pneumocapillary hydraulic pump; fluid is infused at the rate of 0.25 mililiters per minute during $\mathrm{SO}$ recording. The perfusate is generally distilled water, although physiologic saline needs further evaluation. The latter may crystallize in the capillary tubing of perfusion pumps and must be flushed out frequently. ${ }^{1}$

SOM requires selective cannulation of the bile duct and/or pancreatic duct (Fig. 3A). The duct entered can be identified by gently aspirating on any port. The appearance of yellow-colored fluid in the endoscopic view indicated entry into the bile duct (Fig. 3B). Clear aspirate indicates the entrance to the pancreatic duct. Some investigators prefer to obtain a cholangiogram and/or pancreatogram prior to performing SOM as certain findings may

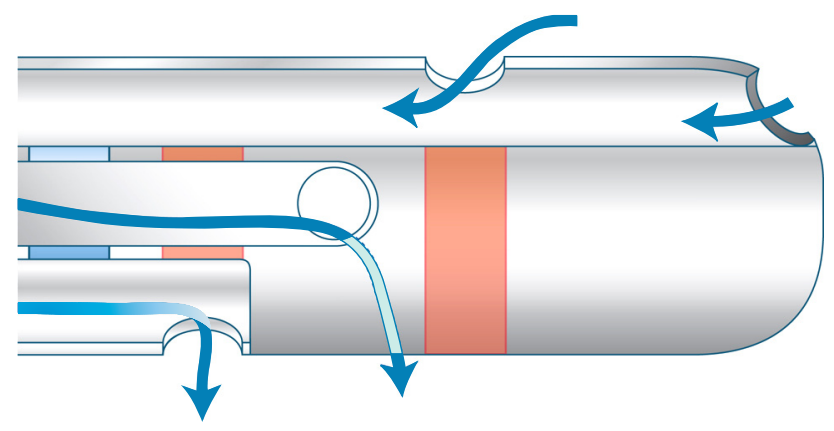

Figure 2. Aspirating sphincter of Oddi manometry catheter. A modified catheter that allows continuous decompression by gentle syrige aspiration through an end hole and side hole, while recording pressures from 2 other ports. 

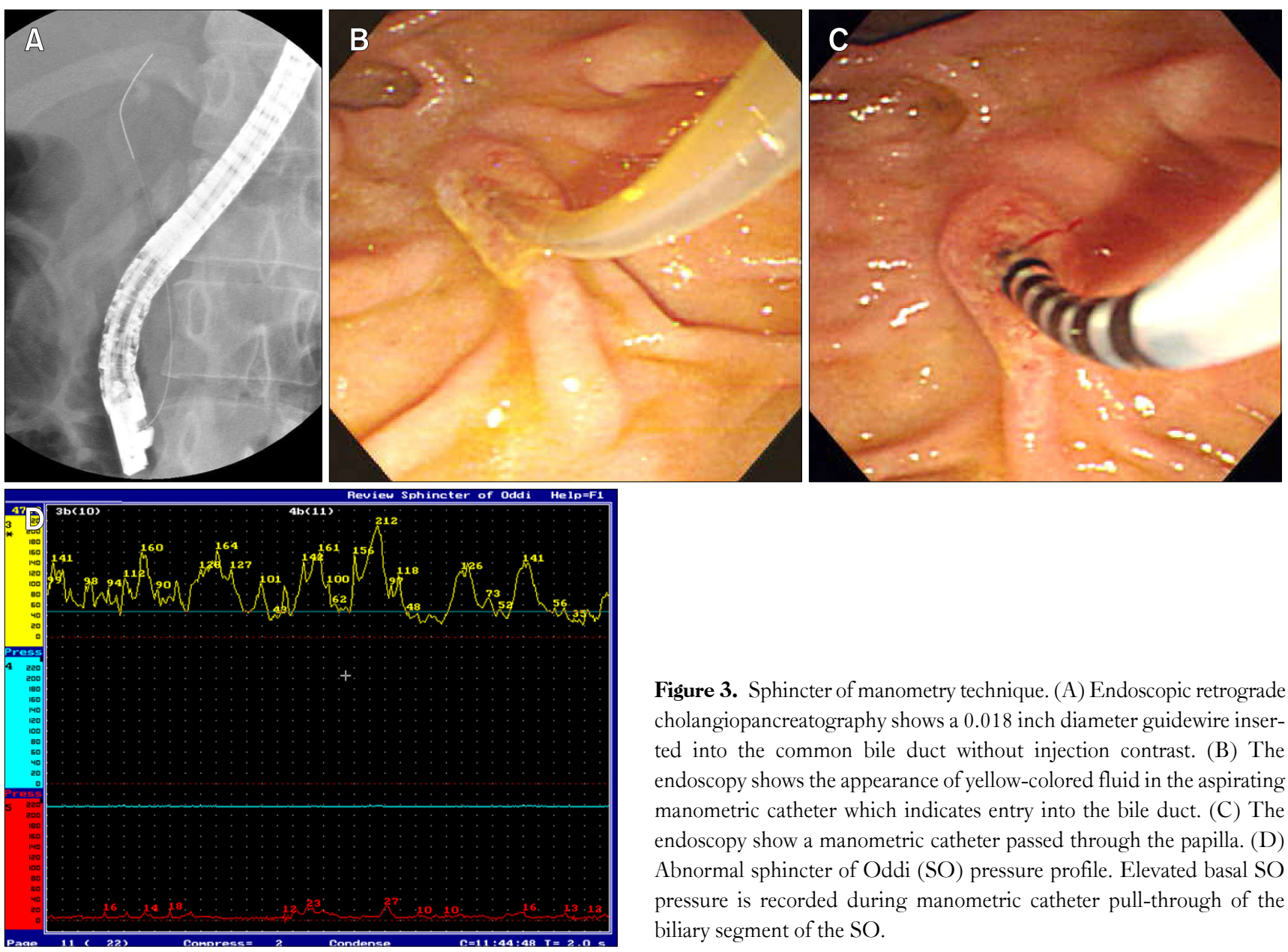

Figure 3. Sphincter of manometry technique. (A) Endoscopic retrograde cholangiopancreatography shows a 0.018 inch diameter guidewire inserted into the common bile duct without injection contrast. (B) The endoscopy shows the appearance of yellow-colored fluid in the aspirating manometric catheter which indicates entry into the bile duct. (C) The endoscopy show a manometric catheter passed through the papilla. (D) Abnormal sphincter of Oddi (SO) pressure profile. Elevated basal SO pressure is recorded during manometric catheter pull-through of the biliary segment of the SO.

obviate the need for SOM. However, I do not recommend the contrast injection into the bile duct and/or pancreatic duct prior to performing SOM since contrast injection may affect SO motility and develop pancreatitis. Once deep cannulation is achieved and the catheter is withdrawn across the sphincter at 1-2 mm intervals by standard station pull-through technique until a phasic high-pressure zone is located, then the high pressure zone is recorded, pausing 30 to 60 seconds at each station where the maximum activity is present (Fig. 3C-D). During pressure recordings, catheter position is continuously monitored endoscopically by observing the position of the catheter marks relative to the papillary orifice.

\section{Normal Values for Sphincter of Manometry -}

The best study establishing normal values for SOM was reported by Guelrud et al. ${ }^{16}$ Fifty asymptomatic control subjects were evaluated, and the normal values for intraductal pressure,
Table 2. Suggested Standard for Abnormal Values for Endoscopic SOM Obtained From 50 Volunteers Without Abnormal Symptoms ${ }^{\text {a }}$ (Adapted from Guelrud et $\mathrm{al}^{16}$ )

\begin{tabular}{ll}
\hline Basal sphincter pressure $^{\mathrm{b}}$ & $>35 \mathrm{mmHg}$ \\
Basal ductal pressure & $>13 \mathrm{mmHg}$ \\
Phasic contractions & $>220 \mathrm{mmHg}$ \\
Amplitude & $>8 \mathrm{sec}$ \\
Duration & $>10 / \mathrm{min}$ \\
Frequency &
\end{tabular}

${ }^{a}$ Values were obtained by adding 3 deviations to the mean (means were obtained by averaging the results on 2 or 3 station pull-throughs). Data combine pancreatic and biliary studies. ${ }^{b}$ Basal pressures determined by (1) reading the peak basal pressure (ie, the highest single lead as obtained using a 3 lumen catheter) and (2) obtaining the mean of these peak pressures from multiple station pull-throughs.

basal sphincter pressure, and phasic wave parameters were established (Table 2). Also, the reproducibility of SOM was confirmed. 


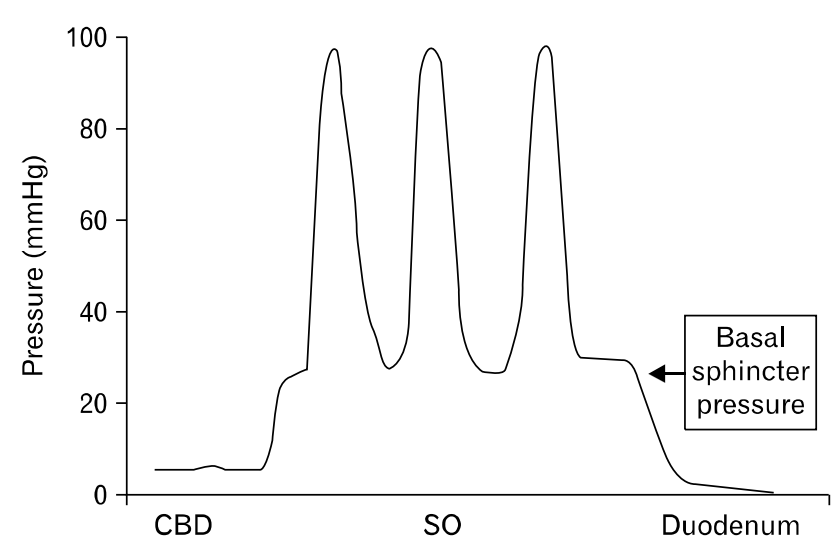

Figure 4. Schematic representation of a sphincter of Oddi manometry recording. Note that the basal sphincter pressure is the baseline pressure between phasic waves (using the duodenal pressure as the zero reference point). Adapted from Sherman et al. ${ }^{15} \mathrm{CBD}$, common bile duct; SO, sphincter of Oddi.

\section{Interpretation of a Sphincter of Tracing -}

After each ductal and pull-through recording, duodenal pressure is measured as the zero reference. Alternatively, intraduodenal pressure can be continuously recorded from a separate intraduodenal catheter attached to the endoscope. However, the latter is a cumbersome process. First, identify the highest basal pressure (Fig. 4) that is sustained for at least 30 seconds (and preferably over 1 minute). ${ }^{1}$ Then take the 4 lowest amplitude points in that zone and take the mean of these readings as the basal sphincter pressure for the highest basal pressure lead for a catheter pull-through. Average the basal sphincter pressure for all interpretable observations and take this as the final basal sphincter pressure. The ampiltude of phasic wave contractions is measured from the beginning of slope of the pressure increase from basal pressure to peak of the contraction wave. Four representative waves are taken from each lead and the mean pressure is determined. The number of phasic waves per minute and the duration can also be determined. The most important SO manometric feature is the basal SO pressure. Most authorities agree that a basal $\mathrm{SO}$ pressure measurement equal to or greater than $40 \mathrm{mmHg}$ is an abnormal value. It should be emphasized that the only study evaluating "normal healthy subjects" determined an abnormal basal SO pressure as $\geq 35 \mathrm{mmHg}$. ${ }^{16}$ Normal pressure within the pancreatic duct is slightly higher than in the bile duct. Normal pancreatic sphincter pressures are accepted as the same as for the bile duct, however, control data are limited.

\section{Cautions in the Interpretation of Sphincter of Manometry}

There are several important mechanical factors that are acknowledged as having an effect on SO pressures; (1) tip impaction of the manometry catheter against the ductal wall (applying excess force onto the catheter with the endoscope's elevator) and air bubbles within the perfusion system; (2) specific medications are unlikely, but may affect SOM (diazepam, droperidol and meperidine have a token effect on sphincter activity but do not change biliary basal sphincter pressure); ${ }^{17,18}$ and (3) contrast injection into the common bile duct may also affect $\mathrm{SO}$ motility. As a rule, it appears that cholangiography generates pressure modifications within the biliary system, although these changes are likely to be predictably small and probably clinically insignificant. $^{19}$

During fasting, the motility of the intestine in most nonruminant animals exhibits a cyclic change called the migrating motor complex. ${ }^{20}$ Carlson et $\mathrm{al}^{21}$ divided each cycle of this variation into 4 phases. Phase I is characterized by the relative absence of contraction. Phase II consists of pregressively increasing, intermittent contractile activity. Phase II culminates abruptly in phase III, which is characterized by regular, high-amplitude contractions. Phase IV is a short transitional period back to another period of quiescence in phase I. The period of a complete cycle is around 100 minutes in humans. ${ }^{22}$ In duodenal phase I, the SO shows irregular myoelectric activity and irregular contractions by manometry even when the duodenum is quiescent. SO basal pressure and common bile duct pressure is high during this phase. ${ }^{23}$ In duodenal phase II, the SO shows increasing myoelectric activity and more powerful and frequent contractions by manometry. In duodenal phase III, the SO exhibits regular strong myoelectric and contractile activity. The SO contractions are most powerful and frequent during this phase. Because of the similarity of motility in the duodenum and SO during phase III, some authors have considered that the SO did not have independent motility. ${ }^{24}$ However, the fact that the SO continues to contract during the quiescence of duodenal phase I supports the independent nature of SO motility. ${ }^{25}$

\section{Limitations}

The limitations of SOM performed during ERCP are those posed by altered upper gastrointestinal tract anatomy. Although 
SOM can be performed intraoperatively and percutaneously, it is most commonly done in the ERCP setting. Experienced endoscopic skills are required to cannulate the appropriate ductal system and to perform SOM carefully. It is essential that the endoscopist has the appropriate patience and interest to adequately complete the study.

\section{Complications}

SOM is combined with a diagnostic ERCP examination. This complexity of procedures often compounds the complication rate. Most common major complication after SOM is acute pancreatitis. Using standard perfused catheters, pancreatitis rates as high as $31 \%$ have been reported. ${ }^{26}$ On rare occations, the pancreatitis may be very severe and life threatening. The morbidity associated with this study increases if the pancreatic duct is cannulated and pressures are recorded from the pancreatic duct segment of the SO. The incidence of pancreatitis has been shown to be reduced with lower rates of manometric catheter perfusion ${ }^{27}$ or by use of one of the manometric catheter as an aspirating port rather than as a measurement channel. ${ }^{15}$ This latter approach decreases the incidence of post-ERCP pancreatitis following pancreatic duct manometry. Recently, microtransducer manometry system has been developed. ${ }^{28}$ The electronic microtransducer manometry system assembly consistes of a 4-Fr catheter, solid-state catheter (SSC), with an atraumatic metal tip (UniTip gastrointestinal pressure sensor catheter, Unisensor; Standard Instruments, Karlsruhe, Germany). The catheter is connected to a small portable instrument, which features a display to allow real-time observation of the pressure recording during endoscopy. SOM with SSC may lead to a decreased risk of post-ERCP pancreatitis, as no water is infused into the pancreatic duct during pressure measurements. ${ }^{29}$

\section{Conclusion}

Despite the recent dramatic advances in the understanding of SO function, many unresolved physiological and clincal issues remain. SOM has aided the understanding of the pressure dynamics of the SO. The creation of the hydraulic-capillary manometry system, a low compliance system highly sensitive to sudden pressure changes, permitted accurate manometry of the SO. SOM has become a useful diagnostic tool in evaluating patients with unexplained pancreatico-biliary pain or idiopathic pancreatitis. SOM is highly recommended for type II patients and is man- datory for all type III patients if sphincter ablation is contemplated. Other causes of abdominal pain such as chronic pancreatitis or functional disordrs should be considered in patients not benefiting from sphincter ablation. SOM requires endoscopist's experience and is a invasive procedure. For now, SOM in the evaluation of chronic abdominal pain should be limited to patients with evidence suggestive of SOD.

\section{References}

1. Sherman S, Lehman GA. Sphincter of Oddi dysfunction: diagnosis and treatment. JOP 2001;2:382-400.

2. Varadarajulu S, Hawes R. Key issues in sphincter of Oddi dysfunction. Gastrointest Endosc Clin N Am 2003;13:671-694.

3. Chuttani R, Carr-Locke DL. Pathophysiology of sphincter of Oddi. Surg Clin North Am 1993;73:1311-1322.

4. Toouli J. Sphincter of Oddi. Gastroenterologist 1996;4:44-53.

5. Hogan WJ, Sherman S, Pasricha P, Carr-Locke D. Sphincter of Oddi manometry. Gastrointest Endosc 1997;45:342-348.

6. Behar J, Corazziari E, Guelrud M, Hogan W, Sherman S, Toouli J. Functional gallbladder and sphincter of Oddi disorders. Gastroenterology 2006;130:1498-1509.

7. Eversman D, Fogel FL, Rusche M, Sherman S, Lehman GA. Frequency of abnormal pancreatic and biliary sphincter manometry compared with clinical suspicion of sphincter of Oddi dysfunction. Gastrointest Endosc1999;50:637-641.

8. Tarnasky PR, Cunninghan JT, Knapple WL, et al. Repeat pancreatic sphincteroter manometry after biliary sphincterotomy in patients with sphincter of Oddi dysfunction. Gastrointest Endosc 1997;45: AB151.

9. Cheon YK, Cho YD, Moon JH, et al. Effects of vardenafil, a phosphodiesterase type- 5 inhibitor, on sphincter of Oddi motility in patients with suspected biliary sphincter of Oddi dysfunction. Gastrointest Endosc 2009;69:1111-1116.

10. Ponce Garciia J, Garrigues V, Sala T, Pertejo V, Berenguer J. Diazepam does not modify the motility of the sohincter of Oddi. Endoscopy 1988;20:87.

11. Staritz M, Meyer K. Investigation of the effect of diazepam and other drugs on the sphincter of Oddi motility. Ital J Gastroenterol 1986;25: 384-386.

12. Fazel A, Burton FR. A controlled study of the effect of midazolam on abnormal sphincter of Oddi motility. Gastrointest Endosc 2002;55: 637-640.

13. Baron TH, Dalton CB, Cotton PB, et al. The effect of propofol on the canine sphincter of Oddi. HPB Surg 1994;7:297-304.

14. Sherman S, Gottlieb K, Uzer MF, et al. Effects of meperidine on the pancreatic and biliary sphincter. Gastrointest Endosc 1996;44:239242.

15. Sherman S, Troiano FP, Hawes RH, Lehman GA. Sphincter of Oddi manometry: decreased risk of clinical pancreatitis with use of a modified aspirating catheter. Gastrointest Endosc 1990;36:462-466.

16. Guelrud M, Mendoza S, Rossiter G, Villegas MI. Sphincter of Oddi manometry in healthy volunteers. Dig Dis Sci 1990;35:38-46.

17. Staritz M. Pharmacology of the sphincter of Oddi. Endoscopy 1988; 
20:171-174.

18. Fogel EL, Sherman S, Bucksot L, Shelly L, Lehman GA. Effects of droperidol on the pancreatic and biliary sphincter. Gastrointest Endosc 2003;58:488-492.

19. Ronly P, Funch-Jensen P, Kruse A, Thommesen P. Effect of cholecystectomy on the relationshop between hydrostatic common bile duct pressure and sphincter of Oddi motility. Endoscopy 1991;23: 111-113.

20. Szurszewski JH. A migrating electric complex of the canine small intestine. Am J Physiol 1969;217:1757-1763.

21. Carlson GM, Bedi BS, Code CF. Mechanism of propagation of intestinal interdigestive myoelectric complex. Am J Physiol 1972;222: 1027-1030.

22. Tanaka M, Ogawa Y, Yokohata K. A method to correlate common bile duct pressure and the migrating motor complex of the duodenum. Gastrointest Endosc 1990;36:497-500.

23. Yokohata K, Kimura H, Ogawa Y, Naritomi G, Tanaka M. Biliary motility: changes in detailed characteristics correlated to duodenal migrating motor complex and effects of morphine and motilin in dogs. Dig Dis Sci 1994;39:1294-1301.

24. Mochinaga N, Sarna SK, Condon RE, Dodds WJ, Matsumoto T.
Gastroduodenal regulation of common duct bile flow in the dog. Gastroenterology 1980;94:755-761.

25. Yokohata K, Tanaka M. Cyclic motility of the sphincter of Oddi. J Hepatobiliary Pancreat Surg 2000;7:178-182.

26. Piccinni G, Angrisano A, Testini M, Bonomo GM. Diagnosing and treating sphincter of Oddi dysfunction: a critical literature review and reevaluation. J Clin Gastroenterol 2004;38:350-359.

27. Meshkinpour H, Kay L, Mollot M. The role of the flow rate of the pneumohydraulic system on post-sphincter of Oddi manometry pancreatitis. J Clin Gastroenterol 1992;14:236-239.

28. Wehrmann T, Schmitt T, Schönfeld A, Caspary WF, Seifert H. Endoscopic sphincter of Oddi manometry with a portable electronic microtransducer system: comparison with the perfusion manometry method and routine clinical application. Endoscopy 2000;32:444451.

29. Wehrmann T, Stergiou N, Schmitt T, Dietrich CF, Seifert H. Reduced risk for pancreatitis after endoscopic microtransducer manometry of the sphincter of Oddi: a randomized comparison with the perfusion manometry method technique. Endoscopy 2003;35:472477. 